\title{
Prevalence, subtypes and risk factors of Blastocystis spp. infection among pre- and perimenopausal women
}

\author{
Danuta Kosik-Bogacka ${ }^{1}$, Małgorzata Lepczyńska², Karolina Kot ${ }^{3 *}$, Małgorzata Szkup ${ }^{4}$, \\ Natalia Łanocha-Arendarczyk ${ }^{3}$, Ewa Dzika ${ }^{2}$ and Elżbieta Grochans ${ }^{4}$
}

\begin{abstract}
Background: Blastocystis spp. are considered pathogenic or commensal organisms, although the majority of researchers suggest that these are neglected pathogens. The main aim of this study was to determine the prevalence and subtype distribution of Blastocystis spp. in pre- and perimenopausal women, with respect to socio-demographic (age and place of residence), and epidemiological factors, as well as drinking tap water, contact with domestic animals, traveling abroad, health status, and presence of gastrointestinal symptoms. Additionally, the objective was to compare hematological and biochemical parameters of Blastocystis spp. infected and uninfected women.
\end{abstract}

Methods: The study included 425 women aged 45-60. Their stool samples were examined microscopically and analyzed by a conventional polymerase chain reaction (CPCR).

Results: Blastocystis spp. were detected in $6.1 \%$ of pre- and perimenopausal women. Molecular analysis of the stool samples identified seven Blastocystis subtypes (ST1-ST4, ST6, ST7, and ST9). Blastocystis subtypes 2 and 3 were the most prevalent. The presence of Blastocystis spp. was not significantly related to socio-demographic and epidemiological factors. There were also no significant associations between Blastocystis spp. and blood parameters, or gastrointestinal symptoms.

Conclusion: This study complements the limited available data on the prevalence of Blastocystis spp. in pre- and perimenopausal women. It is also the first report showing the presence of Blastocystis subtype 9 in Poland.

Keywords: Blastocystis subtypes, Socio-demographic and epidemiological factors, Hematological profile, Pre- and perimenopausal women

\section{Background}

Blastocystis spp. are enteric protozoa of humans and many animals, including mammals, birds, reptiles, amphibians, and insects [1-3]. Blastocystis spp. are considered pathogenic or commensal organisms, although the majority of researchers suggest that these are

\footnotetext{
*Correspondence: karolina.kot@pum.edu.pl

${ }^{3}$ Department of Biology and Medical Parasitology, Pomeranian Medical University in Szczecin, Powstanców Wielkopolskich 72, 70-111 Szczecin, Poland

Full list of author information is available at the end of the article
}

neglected pathogens [4]. The prevalence of Blastocystis spp. infection was of ranges from 22 to $56 \%$ in European countries [5-7], whereas in Asian and African countries the rate is $37 \%$ to $100 \%$ [8-10].

Some researchers suggest that the risk of Blastocystis spp. infection increases with age, as Blastocystis spp. have been found most frequently in patients aged between 30 and 60 years [11-13] Based on research conducted among $\geq 65$-year-old nursing home residents, Arserim et al. [14] noticed that intestinal infections are a common problem in the elderly, with Blastocystis spp. being the 
most common pathogens detected in the stool. Infections in the elderly can be associated with atypical symptoms. The reason for this could be the weakening of cellular and humoral immunity, caused by the effect of aging on the gut microbiota. In addition, the risk of intestinal infections in the elderly is increased by the elevated prevalence of chronic diseases in this age group [14].

Blastocystis spp. are polymorphic parasites with multiple morphological forms including vacuolar, multivacuolar, avacuolar, granular, ameboid, and cyst $[15,16]$. The cyst form is considered to represent the infectious stage; its transmission takes place via the fecal-oral route and can occur via contaminated water or food, human-tohuman contact, or animal-to-human contact $[1,17,18]$. Studies using a rat model have demonstrated that the infective dose must contain at least 10 cysts [19].

Blastocystis spp. have been observed in Scottish and Malaysian sewage samples [20] and ready-to-eat package salads in Italy [21]. The description of two suspected waterborne outbreaks of blastocystosis [22, 23], and the chlorine insensitivity of Blastocystis spp. cysts implicate chlorinated drinking water as a potentially significant transmission route $[24,25]$.

Pathogenicity, mode of transmission, genetic diversity, host specificity, and treatment of Blastocystis spp. infections are still not well understood [26]. Blastocystis spp. have been observed in ulcers in the cecum, transverse colon, and rectum of an immunocompetent individual [27]. They can also obstruct the appendiceal lumen [28]. The pathogenicity of Blastocysis spp. probably depends on the duration (acute or chronic) and intensity of infection, host genetic factors, or Blastocystis subtypes [29, 30].

To date, 22 subtypes (ST1-ST22) of Blastocystis spp. have been identified, based on the sequence analysis of the small subunit ribosomal RNA gene, with 10 (ST1 to ST9 and ST12) reported in humans of which ST3 is the most commonly detected subtype [31].

Blastocystis spp. infection causes blastocystosis [32]. The common symptoms including chronic and acute diarrhea, abdominal pain, nausea, vomiting, anorexia, weight loss, and dermatological symptoms (e.g., rash, itching, and urticaria) [33, 34].

The Blastocystis spp. infection is usually diagnosed using direct-light microscopy, trichrome staining, or xenic in vitro cultures. Molecular diagnosis by polymerase chain reaction (PCR) is becoming more widely used for the detection of Blastocystis spp. This method is costly but more sensitive than the direct smear and xenic culture [35]. A recent study suggests that the direct fluorescent antibody method has a higher sensitivity than native-Lugol examination and is fast and practical compared to other methods [36].
The gut microbiota plays role in maintaining a mucosal barrier, colonization of pathogens, and contributing to immune homeostasis [37]. In general, postmenopausal women show reduced immune system resistance to encountered infectious pathogens, resulting in an increased risk of inflammation [38]. Zhao et al. [39] were observed alterations of gut microbiota in postmenopausal women. Blastocystis spp. play a role in the ecology of the gut microbiota through their interaction with other microbial components [40]. It has been found that subtype ST7 potentially leads to an imbalance in the intestinal microbiota [41, 42]. We hypothesized that in postmenopausal women, there is an increased risk of Blastocystis spp. infection and clinical symptoms. The main aim of this study was to determine the prevalence and subtype distribution of Blastocystis spp. in pre- and perimenopausal women, with respect to socio-demographic (age and place of residence), and epidemiological factors, as well as drinking tap water, contact with domestic animals, traveling abroad, health status, and presence of gastrointestinal symptoms. Additionally, the objective was to compare hematological and biochemical parameters of Blastocystis spp. infected and uninfected women.

\section{Methods \\ Participants}

The study included 425 women aged 45-60 (mean age $54.3 \pm 4.2$ years) from the West Pomeranian Voivodeship (Poland) who had volunteered after receiving information about the study from local papers and information posters in public places. A detailed description of the study sample was presented by Szkup et al. [43].

The criteria for inclusion in the study were: female aged between 45 and 60 years with no current cancerous, psychiatric, or inflammatory diseases, and explicit written consent to take part in the study. Patients who had taken antibiotics, anti-diarrhea compounds, barium, bismuth, or mineral oil ( $\leq 3$ weeks) were excluded.

Each participant had to fill a questionnaire. The questionnaire was given to each participant to obtain sociodemographic (age and urban/rural residence), and epidemiological data, such as type of water supply, contact with domestic animals, place of spending holidays (Poland or abroad), health status, presence of gastrointestinal symptoms such as abdominal pain, diarrhea, abdominal cramps, nausea, bloating and constipation, and chronic diseases.

\section{Assessment}

\section{Stool examination}

The participants received stool sample containers and standard instructions on the proper and safe collection 
and preservation of the samples. Urine free stool samples were collected in a clean, dry, and leak-proof container.

The stool samples collected from all patients were examined macroscopically in terms of consistency, and presence of blood, and helminths. During the microscopic examination of the stools, approximately $2 \mathrm{~g}$ of stool sample was mixed with a drop of saline solution $(0.9 \%)$ and Lugol's iodine (diluted in 1:5 distilled water). The intensity of Blastocystis spp. infection using a $\times 40$ magnification was determined using four levels of parasite load: (1) very low-single protozoans in the whole preparation, (2) low-single protozoans in almost every field of vision, (3) medium -5 to 10 protozoans in every field of vision, (4) high $->10$ protozoans in every field of vision. Taking into consideration that microscopy requires skilled personnel to recognize different morphological forms without information about the subtypes, the positive and unsure samples by this method were tested using the CoproELISA Blastocystis test (Savyon Diagnostics Ltd, Israel) to detect Blastocytis spp. antigens. The samples positive in ELISA and/or microscopic method were subjected to conventional PCR (cPCR).

\section{Molecular assays}

For molecular analysis, the stool was stored in $70 \%$ ethanol. The samples were washed three times in phosphatebuffered saline (PBS) prior to DNA extraction. DNA extraction was performed using the Sherlock AX (A\&A Biotechnology, Poland) kit to perform conventional CPCR according to the manufacturer's instructions.

The method used for detecting Blastocystis spp. in the samples and subtype analysis involved $\mathrm{CPCR}$ with the primers RD5 (5'-ATCTGGTTGATCCTGCCA GT-3'), and BhRDr (3'-GAGCTTTTTAACTGCAAC AACG-5') amplifying a 600-base pair (bp) fragment of the $1.8 \mathrm{kbp}$ small subunit ribosomal RNA (SSU rRNA) gene [44]. This region of the SSU-rRNA gene has been shown to provide sufficient information for differentiating subtypes of Blastocystis [44]. $2 \mu \mathrm{L}$ of extracted DNA was added to an amplification mixture containing $1 \mu \mathrm{l}$ $(10 \mu \mathrm{M})$ of primers and $12.5 \mu \mathrm{l}$ of PCR Master Mix Plus (A\&A Biotechnology, Poland). To each mixture, nuclease-free water was added to provide a final reaction volume of $25 \mu$ l. Sterile water was used as a negative control, and Blastocystis ST2 DNA, diluted to 1:100 obtained from the stool samples of colonized volunteers, was used as a positive control. The amplification profile consisted of 30 cycles of denaturation, annealing and extension at $94{ }^{\circ} \mathrm{C}, 59^{\circ} \mathrm{C}$ and $72{ }^{\circ} \mathrm{C}$ respectively, with a final extension step of $2 \mathrm{~min}$ at $72{ }^{\circ} \mathrm{C}$. PCR products $(5 \mu \mathrm{l})$ were analyzed on $1.35 \%$ agarose gel using electrophoresis and visualized with UV light. Positive PCR products were purified using
Clean-Up (A\&A Biotechnology, Poland) according to the manufacturer's recommendations.

Sequencing on the samples subject to CPCR was done once using Macrogen Humanizing Genomics Europe (Amsterdam, The Netherlands). Primers used in the experiment: RD5 (5'-ATCTGGTTGATCCTGCCA GT-3'), and BhRDr (3'-GAGCTTTTTAACTGCAAC AACG-5'). Sequences were edited and assembled using Finch TV v 1.4 (Geospiza Inc., Seattle, WA, USA). The sequences were analyzed by the BLAST website (https:// blast.ncbi.nlm.nih.gov/Blast.cgi?PAGE_TYPE = Blast Search). STs and ST (SSU-rDNA) alleles were called using the sequence query facility in the Blastocystis Sequence Typing website available at http://pubmlst.org/ Blastocystis/. Subtypes were identified by determining the exact match or closest similarity to all known Blastocystis subtypes according to the classification by Stensvold et al. [35].

\section{Laboratory parameters}

The blood samples were taken from the antecubital vein on an empty stomach (at least $8 \mathrm{~h}$ from the last meal) from each patient between 7.00 and 9.30 in the morning, after $10 \mathrm{~min}$ of chair-seated rest. The blood was collected separately into vacutainer tubes (Sarstedt, Germany): one containing $1 \mathrm{G} / \mathrm{L}$ of K2 EDTA and the other for biochemical analysis of serum $(7 \mathrm{ml})$, in compliance with the relevant regulations. White blood cells (WBC), red blood cells (RBC), hemoglobin (HGB), hematocrit $(\mathrm{HCT})$, mean corpuscular volume (MCV), mean corpuscular hemoglobin concentration $(\mathrm{MCHC})$, mean corpuscular hemoglobin $(\mathrm{MCH})$, platelet (PLT), neutrophils (NEU), eosinophils (EOS), basophils, (BASO), lymphocytes (LYM), monocytes (MONO) and C-reactive protein (CRP) were recorded. Morphological blood analysis was performed at the Diagnostics Laboratory in the Independent Public Clinical Hospital no. 1 in Szczecin, Poland.

\section{Statistical analysis}

In order to establish possible relationships between Blastocystis spp. infection and socio-demographic and epidemiological data, hematological and biochemical parameters were evaluated using the Independent Samples $t$-Test, the $\chi^{2}$ test, and Odds ratio (OR). The differences were seemed statistically significant at $\mathrm{p}<0.05$.

\section{Results}

In the microscopic examination, 28 women from 425 were found as Blastocystis spp. positive and samples from three participants could not be clearly determined. The ELISA test on positive samples in the microscopy method revealed colonization of Blastocystis in all of the 31 
samples of the examinees. In cPCR analysis, 31 women were tested positive, whereas 26 of the cPCR amplicons were successfully sequenced.

\section{Stool examination}

In the microscopic examination of stool samples, we found only Blastocystis spp; no other intestinal parasites were found in the stool samples. The vacuolar forms of Blastocystis spp. were observed in 28 women. In the stool samples from three participants, similar cells to the vacuolar form of Blastocystis spp. were observed. Nevertheless, they were imprecise and finally identified as Yarrowia lipolytica and bacteria of Citrobacter genus in the molecular method. Two samples, which were surely identified as Blastocystis spp. in the microscopic examination, were identified as the fungal class Saccharomyces or other eukaryote cells using molecular analysis.

\section{Molecular subtyping of Blastocystis isolates}

By cPCR, 31 of the 425 women tested positive with the expected $600 \mathrm{bp}$ fragment of the SSU-rDNA amplified, and 26 of the cPCR amplicons could be successfully sequenced (Fig. 1). The sequences from the remaining five samples indicated amplification of fungal DNA (the fungal class Saccharomyces, most probably Yarrowia lipolytica) as well as other eukaryote cells rather than Blastocystis spp.

The comparison between the representative sequences of Blastocystis subtypes, using the BLAST software, allowed the direct genotyping of the isolates according to the terminology by Stensvold et al. [35]. Blastocystis spp. were identified in 26 samples; seven Blastocystis subtypes (ST1-ST4, ST6, ST7, and ST9) were identified. ST2 and ST3 were the most prevalent subtypes, each found in $7 / 26$ women followed by ST1 in $5 / 26$, ST4 in $3 / 26$. Two participants harbored ST6, and two more were colonized with ST7 and ST9 each.

Comparing diagnostic methods used in the current study it may be assumed that microscopy is one of the reliable methods to detect Blastocystis spp. in the stool samples. However, it should not be used as an ultimate method to identify protozoan parasites, but only as a screening of the samples.

\section{Socio-demographic and epidemiological characteristics of the women}

A survey showed that of all women, $90.6 \%$ lived in urban areas and $9.4 \%$ in rural areas. $88.7 \%$ of respondents reported drinking tap water. Additionally, $96.0 \%$ of women declared having contact with domestic animals, including dogs, cats, guinea pigs, and hamsters (Table 1). We found an association between a place of spending holidays (in the country or traveling abroad) on Blastocystis spp. infection $(\mathrm{p}<0.01)$; an odds ratio is less than 1 (OR 0.17 ) which means that there is a lower chance of Blastocystis spp. infection while traveling abroad than spending holidays in Poland. It is important to point out that not all women answer this question, and statistical analysis was done based on 182 patients.

Analyzing statistical data, it was also observed that women who lived in urban regions or drinking tap water have a bigger chance of getting infected with Blastocystis spp. than those patients who lived in rural areas and don't drink tap water $(\mathrm{OR}>1)$.

\section{Gastrointestinal symptoms}

Patients marked in the questionnaires whether they had gastrointestinal symptoms that may suggest parasitosis. The women mostly complained about fatigue (64\%), headache (53\%), muscle pain (35\%), and abdominal pain (26\%). Table 2 presents all symptoms pointed by the participants. We found no statistically significant differences in symptoms between Blastocystis spp. infected and uninfected participants. However, in two parameters (fatigue and abdominal pain) level of significance was a little over 0.05 , therefore it is recommended to check those parameters in the study conducted on a bigger population.

It was noted that people who have gastrointestinal symptoms, such as vomiting, abdominal pain, fatigue, and muscle pain, have a bigger chance of being infected with Blastocystis spp. than those women without those symptoms $(\mathrm{OR}>1)$.

\section{Biochemical and haematological parameters in the blood} The mean values for hematological and biochemical were within normal limits (Table 3). Fifteen women with low hemoglobin and hematocrit levels were defined as anemic, including one woman infected with Blastocystis ST3. The participant had all parameters lower in the red blood cell's profile that indicate microcytic anemia. Taking into account white blood cell's profile, all Blastocystis spp. infected women had blood parameters in terms of reference values. There was no difference in hematological and biochemical parameters between Blastocystis spp. infected and uninfected participants. Among Blastocystis spp. infected patients, only one woman who was infected with ST2 had a higher level of CRP $(8.38 \mathrm{mg} / \mathrm{l})$.

\section{Blastocystis subtypes and the patients' characteristics}

The characteristics of participants with Blastocystis subtypes is presented in Table 4. Three women, one with ST2 and two with ST3 infection did not complete the questionnaire, therefore in Table 4 are presented only 23 participants out of 26 infected with Blastocystis spp. 


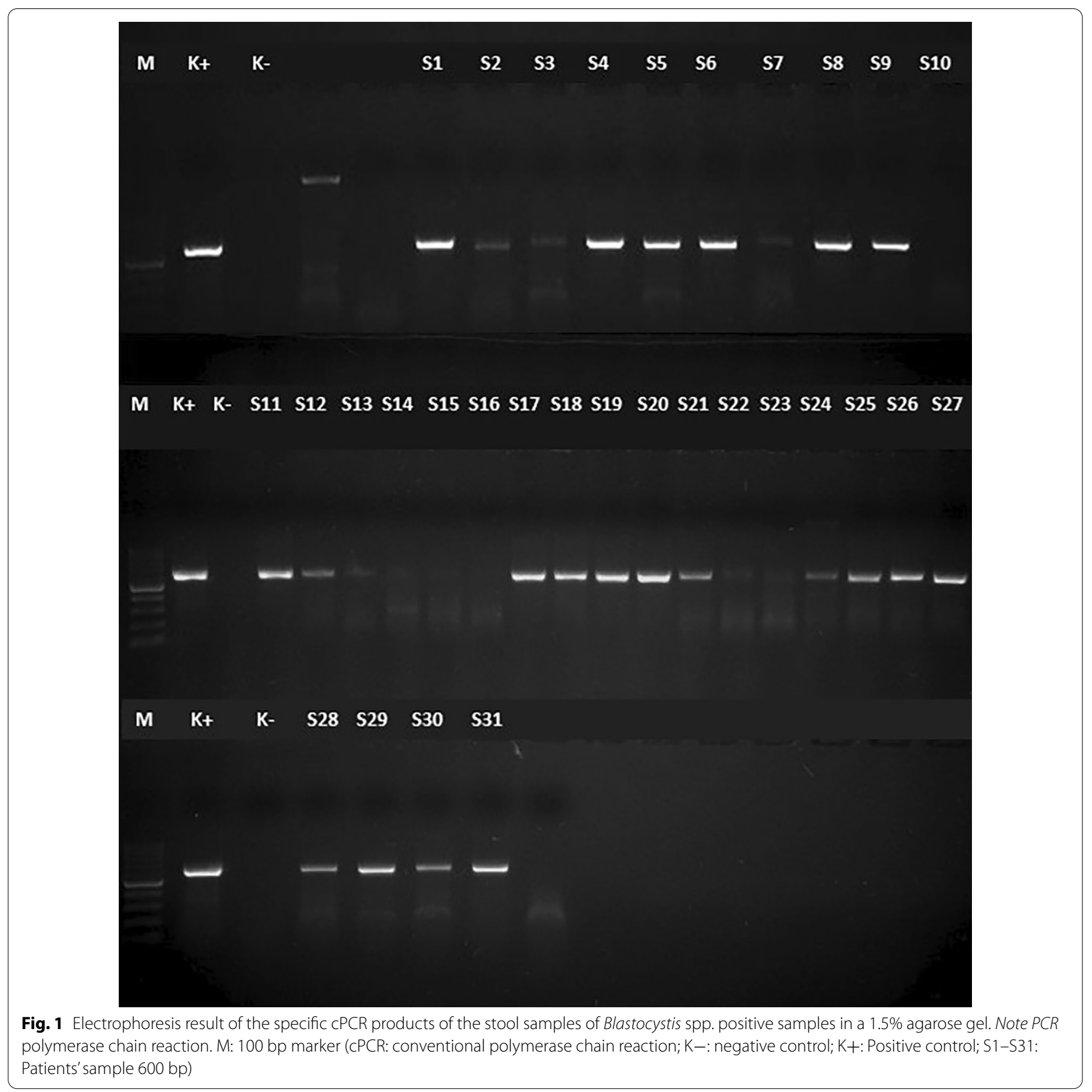

The mean age of the women infected by ST1 was 53.4 years. Four women lived in the city and one in the countryside. All of them drank tap water, had contact with animals, and did not leave the country. Two women had abdominal pain and hypertension.

The average age of the women with ST2 was 51.57 years. All women were city dwellers, drank tap water, and had contact with domestic animals. Two women traveled to tropical countries. Three women had abdominal pain. Four women were diagnosed with thyroid diseases, with one of them also had high blood pressure and one suffered from coronary artery disease.

The mean age of the women with ST3 was 55.4 years. All women came from the city, had contact with domestic animals, and did not leave the country. $87.7 \%$ of the women drank tap water. One woman complained about abdominal pain. One of the women was diagnosed with thyroid disease. 
Table 1 The risk factors of Blastocystis spp. infections (OR, odds ratio; p, level of significance; * due to lack of information from participants, statistics was done based on 182 patients)

\begin{tabular}{|c|c|c|c|c|c|c|c|}
\hline \multirow[t]{2}{*}{ Parameters } & \multicolumn{2}{|c|}{ Blastocystis spp. } & \multirow[t]{2}{*}{$x^{2}$ value } & \multirow[t]{2}{*}{$p$} & \multicolumn{2}{|c|}{ 95\% Confidence } & \multirow[t]{2}{*}{ p } \\
\hline & Positive & Negative & & & OR & Interval & \\
\hline Residence-urban & 22 & 363 & 0.73 & 0.39 & 2.37 & $0.31-18.02$ & 0.41 \\
\hline Traveling abroad* & 2 & 57 & 6.76 & $<0.01$ & 0.17 & $0.04-0.75$ & 0.02 \\
\hline Tap water drinking & 22 & 355 & 1.17 & 0.28 & 2.91 & $0.38-22.11$ & 0.30 \\
\hline Eating unwashed fruits and vegetables & 20 & 355 & 0.04 & 0.85 & 0.88 & $0.25-3.08$ & 0.85 \\
\hline Eating undercooked meat & 15 & 250 & 0.09 & 0.77 & 1.14 & $0.47-2.75$ & 0.77 \\
\hline Contact with domestic animals & 22 & 386 & 0.01 & 0.93 & 0.92 & $0.11-7.19$ & 0.93 \\
\hline Not using gloves during gardening & 6 & 102 & 0.01 & 0.94 & 0.96 & $0.37-2.51$ & 0.94 \\
\hline
\end{tabular}

Table 2 The symptoms reported by Blastocytis spp. infected and uninfected patients (OR, odds ratio; p, level of significance)

\begin{tabular}{|c|c|c|c|c|c|c|c|}
\hline \multirow[t]{2}{*}{ Symptoms } & \multicolumn{2}{|c|}{ Blastocystis spp. } & \multirow{2}{*}{$\begin{array}{l}\mathrm{x}^{2} \\
\text { value }\end{array}$} & \multirow[t]{2}{*}{$p$} & \multicolumn{2}{|c|}{ 95\% Confidence } & \multirow[t]{2}{*}{$p$} \\
\hline & Positive & Negative & & & OR & Interval & \\
\hline Diarrhea & 1 & 52 & 1.47 & 0.23 & 0.31 & $0.04-2.32$ & 0.25 \\
\hline Nausea & 1 & 47 & 1.17 & 0.28 & 0.34 & $0.05-2.61$ & 0.30 \\
\hline Vomiting & 1 & 7 & 0.80 & 0.37 & 2.56 & $0.30-21.76$ & 0.39 \\
\hline Abdominal pain & 10 & 102 & 3.67 & 0.06 & 2.26 & $0.96-5.31$ & 0.06 \\
\hline Weight loss & 1 & 23 & 0.08 & 0.78 & 0.75 & $0.10-5.81$ & 0.78 \\
\hline Fatigue & 19 & 253 & 3.65 & 0.06 & 2.80 & $0.93-8.38$ & 0.07 \\
\hline Loss of appetite & 1 & 21 & 0.03 & 0.85 & 0.82 & $0.11-6.42$ & 0.85 \\
\hline Fever & 1 & 17 & 0.00 & 0.98 & 1.03 & $0.13-8.09$ & 0.98 \\
\hline Enlarged lymph nodes & 1 & 20 & 0.02 & 0.89 & 0.87 & $0.11-6.77$ & 0.89 \\
\hline Flu-like symptoms & 2 & 87 & 2.20 & 0.14 & 0.34 & $0.08-1.50$ & 0.16 \\
\hline Headache & 11 & 213 & 0.23 & 0.63 & 0.81 & $0.35-1.89$ & 0.63 \\
\hline Muscle pain & 12 & 138 & 3.03 & 0.08 & 2.09 & $0.90-4.85$ & 0.09 \\
\hline
\end{tabular}

The average age of the women with subtype 4 was 54.67 years. Two women came from the city, one from a village. They all drank tap water, had contact with domestic animals and did not leave the country. Abdominal pain occurred in two women, including one with hypertension.

Subtype 7 was found in a 45 -year old woman. She was from a large town, had contact with dogs, drank tap water and never left the country.

Subtype 9 was found in a 60-year old woman from a big city who had contact with dogs, did not drink tap water and did not leave the country.

\section{Discussion}

There is no available data in the literature on the prevalence of Blastocystis spp. in pre- and perimenopausal women. But many studies were carried out to examine the prevalence of Blastocystis spp. in groups of participants of different age and gender. In Europe, in patients of Scottish Parasite Diagnostic Laboratory, Glasgow (UK)
Blastocystis spp. infection was detected in $3.9 \%$ of subjects using in vitro culture and direct-light microscopy. The infection was most prevalent in patients between 71 and 80 years of age [45]. In cross-sectional study in Spain, Blastocystis spp. were detected in $7 \%$ of outpatients over 6 years using direct-light microscopy [46]. El-Safadi et al. [47] examined the prevalence of Blastocystis spp. in patients of 11 hospitals throughout France $(n=788)$, who were between 7 months and 95 years (mean age of $45.7 \pm 21.3$ years), using quantitative PCR. The prevalence of Blastocystis spp. was shown to reach $18.1 \%$ [47]. A higher prevalence of Blastocystis spp. (24.2\%) was reported in patients from the Netherlands, including 230 females (median age 29, range 1-82) and 212 males (median age 34 , range $0-87$ years). The authors used the combined gold standard of sequence-confirmed PCR and positive advanced microscopy [5]. In Poland, the prevalence of Blastocystis spp. ranged from $0.89 \%$ in patients at the Laboratory of Department of Biology and Medical Parasitology of the Pomeranian Medical University 
Table 3 The hematological and biochemical profile of Blastocystis spp. infected and uninfected patients (WBC white blood cells; RBC red blood cells; HGB hemoglobin; HCT hematocrit; MCV mean corpuscular volume; MCH mean corpuscular hemoglobin; MCHC mean corpuscular hemoglobin concentration; PLT platelets; NEU neutrophils; LYM lymphocytes; MONO monocytes; EOS eosinophils; BASO basophils; CRP ( reactive protein; $p$ level of significance)

\begin{tabular}{|c|c|c|c|c|c|}
\hline \multirow[t]{2}{*}{ Parameters } & & \multicolumn{2}{|c|}{ Blastocystis spp. } & \multirow[t]{2}{*}{$\mathrm{t}$-Student test } & \multirow[t]{2}{*}{$p$} \\
\hline & & Positive & Negative & & \\
\hline \multirow[t]{3}{*}{ WBC [tys/ul] } & $\mathrm{AM} \pm \mathrm{SD}$ & $6.01 \pm 1.17$ & $6.13 \pm 4.43$ & 0.13 & 0.90 \\
\hline & Median & 6.37 & 5.64 & & \\
\hline & Range & $3.81-7.71$ & $2.30-77.27$ & & \\
\hline \multirow[t]{3}{*}{$\operatorname{RBC}[\mathrm{m} \mid \mathrm{n} / \mu \mathrm{l}]$} & $\mathrm{AM} \pm \mathrm{SD}$ & $4.55 \pm 0.27$ & $4.57 \pm 0.31$ & 0.24 & 0.81 \\
\hline & Median & 4.48 & 4.57 & & \\
\hline & Range & $4.24-5.25$ & $3.77-5.58$ & & \\
\hline \multirow[t]{3}{*}{$\mathrm{HGB}[\mathrm{g} / \mathrm{dl}]$} & $\mathrm{AM} \pm \mathrm{SD}$ & $13.46 \pm 1.08$ & $13.53 \pm 1.02$ & 0.39 & \\
\hline & Median & 13.50 & 13.60 & & 0.70 \\
\hline & Range & $9.50-15.80$ & $8.90-16.40$ & & \\
\hline \multirow[t]{3}{*}{ HCT [\%] } & $\mathrm{AM} \pm \mathrm{SD}$ & $39.14 \pm 2.76$ & $40.90 \pm 27.17$ & 0.32 & 0.75 \\
\hline & Median & 39.40 & 39.00 & & \\
\hline & Range & $30.50-46.30$ & $28.20 \pm 470.70$ & & \\
\hline \multirow[t]{3}{*}{ MCV [f] } & $\mathrm{AM} \pm \mathrm{SD}$ & $86.12 \pm 3.76$ & $85.53 \pm 4.73$ & -0.61 & 0.54 \\
\hline & Median & 86.70 & 86.00 & & \\
\hline & Range & $71.90-92.70$ & $36.50-95.40$ & & \\
\hline \multirow{3}{*}{$\mathrm{MCH}[\mathrm{pg}]$} & $\mathrm{AM} \pm \mathrm{SD}$ & $29.60 \pm 1.75$ & $29.60 \pm 2.05$ & 0.00 & 1.00 \\
\hline & Median & 29.80 & 30.00 & & \\
\hline & Range & $22.40-31.80$ & $7.90-33.60$ & & \\
\hline \multirow[t]{3}{*}{$\mathrm{MCHC}[\mathrm{g} / \mathrm{dl}]$} & $\mathrm{AM} \pm \mathrm{SD}$ & $34.35 \pm 0.85$ & $35.32 \pm 15.10$ & 0.32 & 0.75 \\
\hline & Median & 34.50 & 34.60 & & \\
\hline & Range & $31.10-35.60$ & $30.80-352.00$ & & \\
\hline \multirow[t]{3}{*}{$\mathrm{PLT}[\mathrm{K} / \mu \mathrm{l}]$} & $\mathrm{AM} \pm \mathrm{SD}$ & $263.60 \pm 48.90$ & $254.30 \pm 59.40$ & -0.77 & 0.44 \\
\hline & Median & 262.00 & 246.00 & & \\
\hline & Range & 175.00-391.00 & $65.00-630.00$ & & \\
\hline \multirow[t]{3}{*}{$\mathrm{NEU}[\mathrm{K} / \mu \mathrm{l}]$} & $\mathrm{AM} \pm \mathrm{SD}$ & $3.28 \pm 0.89$ & $3.25 \pm .1 .16$ & -0.15 & 0.88 \\
\hline & Median & 3.23 & 3.07 & & \\
\hline & Range & $1.77-4.92$ & $0.97-8.04$ & & \\
\hline \multirow[t]{3}{*}{ LYM [K/Ml] } & $\mathrm{AM} \pm \mathrm{SD}$ & $2.05 \pm 0.65$ & $1.96 \pm 0.80$ & -0.57 & 0.57 \\
\hline & Median & 1.84 & 1.88 & & \\
\hline & Range & $1.41-4.20$ & $0.88-13.70$ & & \\
\hline \multirow[t]{3}{*}{ MONO $[K / \mu l]$} & $\mathrm{AM} \pm \mathrm{SD}$ & $0.48 \pm 0.11$ & $0.46 \pm 0.13$ & -0.54 & 0.59 \\
\hline & Median & 0.49 & 0.44 & & \\
\hline & Range & $0.25-0.72$ & $0.18-0.95$ & & \\
\hline \multirow[t]{3}{*}{$\operatorname{EOS}[K / \mu l]$} & $\mathrm{AM} \pm \mathrm{SD}$ & $0.16 \pm 0.09$ & $0.17 \pm 0.29$ & 0.28 & 0.78 \\
\hline & Median & 0.13 & 0.13 & & \\
\hline & Range & $0.01-0.37$ & $0.00-5.39$ & & \\
\hline \multirow[t]{3}{*}{ BASO $[\mathrm{K} / \mu \mathrm{I}]$} & $\mathrm{AM} \pm \mathrm{SD}$ & $0.03 \pm 0.02$ & $0.23 \pm 4.06$ & 0.23 & 0.81 \\
\hline & Median & 0.03 & 0.03 & & \\
\hline & Range & $0.01-0.08$ & $0.00-85.30$ & & \\
\hline \multirow[t]{3}{*}{ CRP [mg/l] } & $\mathrm{AM} \pm \mathrm{SD}$ & $2.19 \pm 1.79$ & $2.28 \pm 2.71$ & 0.18 & 0.86 \\
\hline & Median & 1.40 & 1.25 & & \\
\hline & Range & $1.00-8.38$ & $1.00-34.80$ & & \\
\hline
\end{tabular}


Table 4 Blastocystis spp. subtype among pre- and perimenopausal women (BMI Body Mass Index)

\begin{tabular}{|c|c|c|c|c|c|c|c|}
\hline Age & Residence & $\begin{array}{l}\text { Tap water } \\
\text { drinking }\end{array}$ & $\begin{array}{l}\text { Contact with } \\
\text { animals }\end{array}$ & $\begin{array}{l}\text { Travelling } \\
\text { abroad }\end{array}$ & Symptoms & BMI & Chronic diseases \\
\hline \multicolumn{8}{|l|}{ ST1 } \\
\hline 58 & Urban & Yes & Yes & No & - & 21.80 & - \\
\hline 46 & Rural & Yes & Yes & No & - & 28.80 & - \\
\hline 65 & urban & Yes & Yes & No & Abdominal pain & 24.90 & Hypertension \\
\hline 46 & Urban & Yes & Yes & No & Abdominal pain & 27.30 & Hypertension \\
\hline 52 & Urban & Yes & Yes & No & - & 25.30 & - \\
\hline \multicolumn{8}{|l|}{ ST2 } \\
\hline 61 & Urban & Yes & Yes & No & Abdominal pain & 20.80 & Thyroid disease, coronary artery diseases \\
\hline 50 & Urban & Yes & Yes & No & - & 31.00 & Thyroid disease, autoimmune disease \\
\hline 49 & Urban & Yes & Yes & Yes & - & 24.60 & - \\
\hline 56 & Urban & Yes & Yes & Yes & Abdominal pain & 36.30 & Hypertension, thyroid disease \\
\hline 48 & Urban & Yes & Yes & No & Abdominal pain & 29.80 & - \\
\hline 54 & Urban & Yes & Yes & No & Abdominal pain & 23.90 & Thyroid disease \\
\hline \multicolumn{8}{|l|}{ ST3 } \\
\hline 56 & Urban & No & Yes & No & - & 35.00 & Thyroid disease \\
\hline 57 & Urban & Yes & Yes & No & - & 25.40 & - \\
\hline 48 & Urban & Yes & Yes & No & - & 28.80 & - \\
\hline 57 & Urban & Yes & Yes & No & Abdominal pain & 24.00 & - \\
\hline 59 & Urban & Yes & Yes & No & - & 22.90 & - \\
\hline \multicolumn{8}{|l|}{ ST4 } \\
\hline 50 & Urban & Yes & Yes & No & Abdominal pain & 29.00 & - \\
\hline 63 & Urban & Yes & Yes & No & Abdominal pain & 24.60 & Hypertension \\
\hline 51 & Urban & Yes & Yes & No & - & 25.30 & - \\
\hline \multicolumn{8}{|l|}{ ST6 } \\
\hline 53 & Urban & Yes & Yes & No & - & 20.00 & - \\
\hline 50 & Urban & Yes & Yes & No & Abdominal pain & 28.80 & - \\
\hline \multicolumn{8}{|l|}{ ST7 } \\
\hline 45 & Urban & Yes & Yes & No & - & 32.80 & - \\
\hline \multicolumn{8}{|l|}{ ST9 } \\
\hline 60 & Urban & Yes & Yes & No & - & 23.90 & - \\
\hline
\end{tabular}

in Szczecin in the years 1983-2012 [48] to about 10\% in young people (average age was 23 years) [49] and children in Olsztyn (NE Poland) [50] in 2010. On the other hand, Płonka and Dzbeński [51] did not detect the presence of Blastocystis spp. in fecal samples of children aged 7 from various regions of Poland. In the present study Blastocystis spp. infection was found in $6.1 \%$ of pre- and perimenopausal women. Negative diagnoses are based solely on microscopy. However, the results of our study and those from other authors are difficult to compare due to the selection of the patients and methods used for the diagnosis of Blastocystis spp. infection. In addition, there are no data for Blastocystis spp. infection in preand perimenopausal women.

\section{Blastocystis subtypes}

In our study, seven Blastocystis subtypes (ST1-ST4, ST6, ST7, and ST9) were identified in pre- and perimenopausal women. Humans in Europe in different age and gender groups are generally infected by Blastocystis spp. subtypes 1, 2, 3 and 4 [52-55]. Subtypes 1 and 2 have low specificity and their infections probably result from animal-to-human contact [58]. They are found in humans and a wide range of animals, including dogs, cats, chickens, cattle, pigs, and non-human primates [59-61].

Some researchers suggest that ST1 is the most pathogenic subtype of Blastocystis spp. Rene et al. [62] found that ST1 was the most common subtype of Blastocystis spp. in patients with diarrhea. Subtype ST1 has been reported from 10.8 to $29 \%$ of patients from Poland [13, $56,63]$. In the study presented here, ST1 was found in 
$19.2 \%$ of Blastocystis spp. infection in pre- and perimenopausal women.

Blastocystis ST2 infections are most often asymptomatic, but gastrointestinal problems and chronic urticaria sometimes happen [64]. In Italy, in mildly symptomatic patients, or those affected by inflammatory bowel disease (IBD), irritable bowel syndrome (IBS), chronic diarrhea, or with different immunosuppression, ST2 represented $14 \%$ of the isolates [65]. The prevalence of ST2 infection ranged from 9 to $19 \%$ in Poland $[46,56]$. In our study, ST2 was found in $26.9 \%$ of Blastocystis spp. infected pre- and perimenopausal women.

Subtype 3 is classified as anthroponotic and is also found in ungulates, dogs, and non-human primates [61, 66]. Forsell et al. [67] concluded that ST3 was more common in males compared to females. Many researchers suggest that ST3 correlates with gastrointestinal symptoms. Blastocystis subtype 3 was detected in the splenic cysts of an immunocompetent woman in Brazil [68]. This subtype of Blastocystis spp. is also the most frequently found in patients from Poland; subtype 3 was found in about $30 \%$ to $65 \%$ of the examined patients $[13,49,63]$. In our study of pre- and perimenopausal women, $26.9 \%$ of Blastocystis spp. represents ST3.

Subtype 4, common in humans and other primates, has also been found in hoofed mammals, rodents, and birds $[54,66]$. ST4 has been associated with infectious diarrhea in European patients [55]. In patients from Denmark with acute diarrhea (lasting more than 2 weeks), ST4 was the most common in Danish Blastocystis-positive patients (76\%) [55]. Kotłowski [63] found this subtype in Polish travelers to the subtropics and tropics, but also in those who had not left the country. In our study, ST4 was found in $11.5 \%$ of Blastocystis spp. infections in pre- and perimenopausal women.

Subtypes $5-8$, most likely of animal origin, have rarely been observed in humans [69]. ST5 is commonly isolated from livestock and is prevalent in Australia's pig farmers [70]. ST6 and ST7 from birds are rarely found in Europe, but frequently in humans reported in Japan, Pakistan, and Egypt. In Poland, ST6 has been detected in hens [71]. El Safadi et al. [46] found ST6 and ST7 in 2.1\% of isolates from patients in 11 hospitals throughout France. Rene et al. [62] found ST6 in one patient with solid stools. Forsell et al. [67], who studied patients from Stockholm (Sweden), found ST7 (1.6\%) in the examined isolates. In the study conducted in central Poland, $8.7 \%$ of Blastocystis spp. isolates were ST6 and 4.3\% were ST7 [56]. In the north of Poland, ST6 and ST7 constituted 3.3\% of isolates each [57]. ST6 and ST7 were found in 7.7\% of premenopausal and $3.8 \%$ of perimenopausal women from the north-west of Poland infected by Blastocystis spp. The ST8 subtype has been observed in animals, such as rodents, birds and arthropods, and in some New World monkeys [58, 72]. Single cases of ST8 have been reported in patients from Denmark [62] and Italy [60]. In this study, none of the pre- and perimenopausal women had ST8.

ST9 has only been found in humans and is characterized by multiple intestinal symptoms. Before our study, in which we found cases of this subtype, it had been identified in patients from Denmark [73] and Iran [74].

\section{High-risk populations}

Low socioeconomic status, poor quality of drinking water, consumption of contaminated food and poor personal hygiene habits are important risk factors for intestinal parasitic infection, including Blastocystis spp. [75, 76]. Paulos et al. [77] found that Blastocystis spp. were detected in urban areas (44\%) more often than in rural areas (33\%). Similarly, Blastocystis spp. were more often detected in residents of urban areas (64.8\%) than of rural areas (35.2\%) in Northern Cyprus [52]. Lepczyńska et al. [13] also found a higher prevalence of Blastocystis spp. in people living in urban areas (68\%). In our study, most of Blastocystis spp. infected pre- and perimenopausal women came from urban areas.

Contamination of drinking water may be the source of Blastocystis spp. infections. It has been shown that Blastocystis spp. cysts can survive in chlorinated water at routine concentrations [78]. Leelayoova et al. [2] reported the presence of Blastocystis spp. subtype 1 in drinking water. Seyer et al. [52] found no significant correlation between the type of drinking water (bottled or tap water) and the prevalence of Blastocystis infection. In our study, more than $90 \%$ of pre- and perimenopausal infected with Blastocystis spp. drank tap water.

Contact with animals involves a higher risk of Blastocystis spp. infection [17, 61]. Zoonotic transmission may be indicated by the high prevalence of Blastocystis spp. in animal handlers [55, 61, 66, 79]. Blastocystosis is a potential zoonosis as suggested by a number of studies that have isolated identical STs of Blastocystis spp. from humans and the animals they are in contact with $[2,17]$. For example, Blastocystis spp. infection has been reported in $42 \%$ of animals and $63 \%$ of zookeepers from the zoo in Western Australia [17]. Some authors suggest the potential role of domestic animals, including dogs and cats, as natural reservoirs of human Blastocystis spp. infection. Blastocystis spp. have been reported in sheltered canine and feline populations (from $\sim 10$ to $70 \%$ ) [80-82]. Blastocystis subtypes 2-5 were found in people and domestic dogs living in an urban community in the Philippines [83]. 
Blastocystis spp. infection and travel to tropical country Research suggests that the risk of Blastocystis spp. infection may increase by traveling to tropical countries due to poor hygiene and sanitation in some areas. Bart et al. [5] observed significantly a higher prevalence of Blastocystis spp. infection in patients returning from tropical countries as compared to patients without travel history. Duda et al. [84] found Blastocystis spp. in $15.3 \%$ of Polish military personnel returning from peacekeeping missions in Iraq and Afghanistan. A prospective, multicenter COMBAT study among Dutch travelers in 2001 [85] showed Blastocystis spp. infection in $36.3 \%$ of subjects. Among patients from France higher prevalence of Blastocystis spp. (27.5\%) was in people who had traveled during the last 12 months than in non-travelers (14.7\%) [46]. In another study [62], the prevalence of Blastocystis spp. among patients with travel-associated diarrhea was significantly higher than among patients with chronic diarrhea. In patients who traveled to tropical countries from Poland, the prevalence of ST2 (22.8\%) was significantly higher than in those who did not leave the country (10\%) [57]. In our study, pre- and perimenopausal women who had recently been in a tropical country had ST2. However, Stensvold et al. [35] did not find any correlation between the subtypes of Blastocystis spp. and travel activity up to three months before stool sampling.

\section{Symptoms and Blastocystis spp. infection}

The pathogenic role of Blastocystis spp. in causing clinical symptoms remains a controversial issue due to the morphology and genetic diversity of protozoa, as well as the different immune responses of the host [86]. It is usually associated with nonspecific gastrointestinal symptoms, including abdominal pain, diarrhea, nausea, vomiting, bloating, anorexia, and, less commonly, urticaria, intense itching [64, 87], and iron deficiency anemia [88-90].

Some researchers have observed Blastocystis spp. infections more frequently in patients with intestinal symptoms than in asymptomatic patients [91, 92]. In Mexico, Diaz et al. [93] found Blastocystis spp. in 7\% of children with diarrhea. The prevalence of Blastocystis spp. in Thai patients with diarrhea was $21 \%$ [94]. In our study, $43.5 \%$ of pre- and perimenopausal women suffered from gastrointestinal symptoms (including abdominal pain), although we found no relationship between Blastocystis spp. infection and gastrointestinal symptoms. Similarly, Seyer et al. [52] did not notice a statistically significant correlation between Blastocystis spp. infection and gastrointestinal symptoms, such as bloating, abdominal pain, abdominal cramps, constipation, diarrhea, and nausea.
The feces of Blastocystis spp. infected patients contain cysts or vacuolar forms. The ameboid form is probably pathogenic and is mostly associated with showing by the patient some symptoms [95]. A large number of parasites in the intestine ( $>5$ parasites per high-power field) also entails gastrointestinal symptoms [3]. In this study, all pre- and perimenopausal women infected with Blastocystis spp. had less than five vacuolar forms per high-power field.

Many studies have been devoted to the correlation between different Blastocystis spp. subtypes and their pathogenic potential. Kaneda et al. [96] suggested that STs 1, 2, and 4 might be responsible for gastrointestinal symptoms. Yan et al. [97] only found ST1 in a group of symptomatic patients. In their study of Spanish patients with acute and chronic diarrhea, Domínguez-Márquez et al. [53] observed ST4, ST2 and ST1 in 94.1\%, 3.9\% and $2 \%$ of the participants, respectively. Mattiucci et al. [65] observed ST3 (46\%), ST4 (21.7\%), ST1 (15.3\%), ST2 (13.8\%), ST6 (3.2\%) and ST8 (0.5\%) in Blastocystis spp. infected mildly symptomatic patients with IBD, IBS, chronic diarrhea, or another immunosuppression. In this study, gastrointestinal symptoms were observed in preand perimenopausal women infected by ST3 and ST4 (both 66.7\%), ST6 (50\%) and ST1 (40\%).

\section{Blastocystis spp. infection and laboratory results of blood}

The pathomechanism of Blastocystis spp. infection is still unknown. Yavasoglu et al. [88] observed a significantly higher rate of Blastocystis spp. infection among patients with iron deficiency anemia (IDA), and so did El Deeb et al. [90] in their study of pregnant women. Another study by El Deeb et al. [98] showed a significantly higher prevalence of Blastocystis spp. in patients with anemia compared to non-anemic patients. Cheng et al. [99] observed lower hemoglobin, hematocrit and neutrophil counts in patients with Blastocystis spp. infection. Some studies explained anemia in infected patients with the fact that cationic ferritin is essential for the endocytic pathway of Blastocystis spp. [100]. However, in our study, similar to Chen et al. [101], we did not find any significant differences in the hematological parameters between Blastocystis spp. infected and uninfected patients. In Blastocystis spp. infected group of patients, only one woman had lower hemoglobin, hematocrit, and MCV parameters which suggest microcytic anemia. Laodim et al. [94] found that Blastocystis spp. infected patients had lower peripheral eosinophils and serum albumin levels. Levy et al. [102] and Nassir et al. [30] also reported that Blastocystis spp. infection is associated with hypoalbuminemia. In the histological examination of the cecum and colon of Blastocystis spp. infected mice, intense inflammatory-cell infiltration, edematous lamina 
propria and mucosal sloughing were observed [103]. It is suggested that Blastocystis spp. are able to change leukocyte levels, and induce the production of inflammatory cytokines $[102,103]$. In our study, there was no difference between white blood cells and CRP levels between Blastocystis spp. infected and uninfected pre- and perimenopausal women. Among Blastocystis spp. infected patients, only one woman who was infected with ST2 had a higher level of CRP. The exact relationship between the hematological and biochemical parameters of blood and blastocystosis needs further analysis.

\section{Blastocystis spp. infection and chronic diseases}

Immunocompromised patients, including those with AIDS/HIV infection, myeloproliferative disorders, and treated with chemotherapy, are more frequently infected with Blastocystis spp. [104]. Blastocystis spp. have been observed in $38 \%$ of patients with AIDS or HIV infection, as found at the Infectious Diseases Department of a tertiary referral university hospital in northern Germany [11] Blastocystis spp. infection (subtypes 3, 4, 6, and 7) was observed in $16 \%$ of patients aged around 55 with hematological malignancies $(\mathrm{HM} ; \mathrm{n}=94)$ in France [105]. Stensvold et al. [55] found Blastocystis spp. in 23\% of AIDS/HIV infected patients from Denmark, including ST3 in 11.5\%, ST1 in 9.4\%, ST1 and ST3 in 2.1\%.

A higher prevalence of Blastocystis spp. has been observed in patients with IBS compared to healthy populations or patients with other gastrointestinal disorders. Studies of IBS patients showed a higher prevalence of ST1, ST3, and ST4 isolates of Blastocystis spp. and ST7 was found to be correlated with IBS. Karasartova et al. [106] detected Blastocystis spp. in 30\% of splenectomized patients.

In this study, $57.1 \%$ of pre- and perimenopausal women with ST2 suffered from a thyroid disease (Hashimoto's disease). Rajič et al. [107] provided evidence that the eradication of Blastocystis spp. can prevent the development of both symptomatic Hashimoto's thyroiditis and chronic urticaria.

This work has certain limitations. We acknowledge that the screening tests were conducted using direct-light microscopy and the CoproELISA Blastocystis test which are characterized by low sensitivity. That's why we cannot assure that the prevalence of Blastocystis spp. in this study was not higher. However, the overall results can be compared with studies using the same test method. There is no control group. Nevertheless, the analysis of Blastocystis spp. subtype allowed us to demonstrate the population structure of Blastocystis spp. and reveal the presence of ST9 in pre- and perimenopausal women. However, the pathogenicity and risk factors of Blastocystis spp. infection in pre- and perimenopausal women are not fully understood and require further research.

\section{Conclusions}

Our study provides new insights into the epidemiology of Blastocystis spp. and the prevalence and ST distribution of the parasite in Poland. Moreover, this research complements the limited available data on the prevalence of Blastocystis spp. in pre- and perimenopausal women.

The study is the first report showing the presence of ST9 in Poland. Our results showed no association between Blastocystis spp. infection and gastrointestinal symptoms as well as biochemical and hematological blood tests. Taking into account specific risk factors, we found that pre- and perimenopausal women who lived in urban regions or drinking tap water have a bigger chance of getting infected with Blastocystis spp. However, further research in this area is needed.

\section{Acknowledgements}

Not applicable.

\section{Authors' contributions}

The following represents the substantial contributions of individual authors: Conceptualization, DKB, MS, ED and EG; methodology, DKB, ML and ED; performing the experiments, DKB, KK, ML and NŁA; analyzing the data, DKB, $\mathrm{KK}$ and $\mathrm{ML}$; writing the manuscript, DKB, ML, MS and KK; providing scientific supervision of manuscript, DKB, ED and EG. All authors have read and agreed to the published version of the manuscript.

\section{Funding}

The Pomeranian Medical University in Szczecin provided financial support (WLBiML-430-01/S/14/2020). The funder had a role in the collection and analysis of data.

\section{Availability of data and materials}

The data of this manuscript is available at https://ppm.pum.edu.pl/info/resea rchdata/PUMec675cc289d448ab9824f6c86805eb87/

\section{Declarations}

Ethics approval and consent to participate

The study was conducted from June 2017 to December 2019 in accordance with the Declaration of Helsinki. The study was approved by the Bioethics Committee of the Pomeranian Medical University in Szczecin, Poland (protocol registered under Order No. KB-0012/181/13 and KB-0012/104/11). Written informed consent was obtained from participants.

\section{Consent for publication}

Not applicable.

\section{Competing interests}

The authors declare that they have no competing interests.

\section{Author details}

${ }^{1}$ Independent Laboratory of Pharmaceutical Botany, Department of Biology and Medical Parasitology, Pomeranian Medical University in Szczecin, Powstanców Wielkopolskich 72, 70-111 Szczecin, Poland. 'Department of Medical Biology, School of Public Health, University of Warmia and Mazury, Żołnierska 14 C, 10-561, Olsztyn, Poland. ${ }^{3}$ Department of Biology and Medical Parasitology, Pomeranian Medical University in Szczecin, Powstanców Wielkopolskich 72, 70-111 Szczecin, Poland. ${ }^{4}$ Department of Nursing, Pomeranian Medical University in Szczecin, Żołnierska 48, 71-210 Szczecin, Poland. 
Received: 23 January 2021 Accepted: 19 October 2021

Published online: 01 November 2021

\section{References}

1. Eroglu F, Koltas IS. Evaluation of the transmission mode of $B$. hominis by using PCR method. Parasitol Res. 2010;107(4):841-5.

2. Leelayoova S, Siripattanapipong S, Thathaisong U, Naaglor T, Taamasri P, Piyaraj P, Mungthin M. Drinking water: a possible source of Blastocystis spp. subtype 1 infection in schoolchildren of a rural community in Central Thailand. Am J Trop Med Hyg. 2008;79(3):401-6.

3. Tan KS. New insights on classification, identification, and clinical relevance of Blastocystis spp. Clin Microbiol Rev. 2008;21(4):639-65.

4. Stensvold CR, Lewis HC, Hammerum AM, Porsbo LJ, Nielsen SS, Olsen KE, Arendrup MC, Nielsen HV, Mølbak K. Blastocystis: unravelling potential risk factors and clinical significance of a common but neglected parasite. Epidemiol Infect. 2009;137(11):1655-63.

5. Bart A, Wentink-Bonnema EM, Gilis H, Verhaar N, Wassenaar CJ, van Vugt $\mathrm{M}$, Goorhuis A, van Gool T. Diagnosis and subtype analysis of Blastocystis spp. in 442 patients in a hospital setting in the Netherlands. BMC Infect Dis. 2013;13:389.

6. Krogsgaard LR, Engsbro AL, Stensvold CR, Nielsen HV, Bytzer P. The prevalence of intestinal parasites is not greater among individuals with irritable bowel syndrome: a population-based case-control study. Clin Gastroenterol Hepatol. 2015;13(3):507-13.

7. Scanlan PD, Stensvold CR, Cotter PD. Development and application of a Blastocystis subtype-specific PCR assay reveals that mixed-subtype infections are common in a healthy human population. Appl Environ Microbiol. 2015;15(12):4071-6.

8. El Safadi D, Gaayeb L, Meloni D, Cian A, Poirier P, Wawrzyniak I, Delbac F, Dabboussi F, Delhaes L, Seck M, et al. Children of Senegal River basin show the highest prevalence of Blastocystis sp. ever observed worldwide. BMC Infect Dis. 2014;14:164.

9. Forsell J, Granlund M, Samuelsson L, Koskiniemi S, Edebro H, Evengård B. High occurrence of Blastocystis sp. subtypes 1-3 and Giardia intestinalis assemblage B among patients in Zanzibar, Tanzania. Parasit Vectors. 2016;9(1):370

10. Popruk S, Udonsom R, Koompapong K, Mahittikorn A, KusolsukT, Ruangsittichai J, Palasuwan A. Subtype distribution of Blastocystis in Thai-Myanmar border, Thailand. Korean J Parasitol. 2015;53(1):13-9.

11. Albrecht H, Stellbrink HJ, Koperski K, Greten H. Blastocystis hominis in human immunodeficiency virus — related diarrhea. Scand J Gastroenterol. 1995;30(3):909-14

12. Sanchez-Aguillon F, Lopez-Escamilla E, Velez-Perez F, Martinez-Flores WA, Rodriguez-Zulueta P, Martinez-Ocaña J, Martinez-Hernandez F, RomeroValdovinos M, Maravilla P. Parasitic infections in a Mexican HIV/ AIDS cohort. J Infect Dev Ctries. 2013;7(10):763-6.

13. Lepczyńska M, Dzika E, Stensvold CR. Genetic diversity of Blastocystis spp. in the human population of the Olsztyn area. Ann Parasitol. 2016:62:28.

14. Arserim SK, Limoncu ME, GündüzT, Balcıoğlu iC. Investigation of intestinal parasites in living nursing home. Turkiye Parazitol Derg. 2019;43(2):74-7

15. Stenzel DJ, Boreham PF. Blastocystis hominis revisited. Clin Microbiol Rev. 1996;9(4):563-84.

16. Tan TC, Suresh KG. Predominance of amoeboid forms of Blastocystis hominis in isolates from symptomatic patients. Parasitol Res. 2006:98(3):189-93.

17. Parkar U, Traub RJ, Vitali S, Elliot A, Levecke B, Robertson I, Geurden T, Steele J, Drake B, Thompson RC. Molecular characterization of Blastocystis isolates from zoo animals and their animal-keepers. Vet Parasitol. 2010;169(1-2):8-17

18. Stensvold CR, Alfellani M, Clark CG. Levels of genetic diversity vary dramatically between Blastocystis subtypes. Infect Genet Evol. 2012;12(2):263-73.

19. Yoshikawa H, Abe N, Wu Z. PCR-based identification of zoonotic isolates of Blastocystis from mammals and birds. Microbiology. 2004;150(Pt5):1147-51.

20. Suresh K, Smith H, Tan T. Viable Blastocystis cysts in Scottish and Malaysian sewage samples. Appl Environ Microbiol. 2005;71(9):5619-20.
21. Caradonna T, Marangi M, Del Chierico F, Ferrari N, Reddel S, Bracaglia G, Normanno G, Putignani L, Giangaspero A. Detection and prevalence of protozoan parasites in ready-to-eat packaged salads on sale in Italy. Food Microbiol. 2017;67:67-75.

22. Nimiri LF. Evidence of an epidemic of Blastocystis hominis infections in preschool children in northern Jordan. J Clin Microbiol. 1993;31(10):2706-8.

23. Nimiri LF, Batchoun R. Intestinal colonization of symptomatic and asymptomatic school children with Blastocystis hominis. J Clin Microbiol. 1994;32(11):2865-6.

24. Roberts T, Stark D, Harknes J, Ellis J. Update on the molecular epidemiology and diagnostic tools for Blastocystis sp. J Med Microb Diagn. 2014;3(1):131.

25. Zaki M, Zaman V, Sheikh NA. Resistance of Blastocystis hominis cysts to chlorine. JPMA. 1996;46(8):178-9.

26. Noël C, Peyronnet C, Gerbod D, Edgcomb VP, Delgado-Viscogliosi P, Sogin ML, Capron M, Viscogliosi E, Zenner L. Phylogenetic analysis of Blastocystis isolates from different hosts based on the comparison of small-subunit rRNA gene sequences. Mol Biochem Parasitol. 2003;126(1):119-23.

27. Janarthanan S, Khoury N, Antak F. An unusual case of invasive Blastocystis hominis infection. Endoscopy. 2011;43:E185-6.

28. Lintong PM, Sambuaga MK, Tambajong EH. Acute suppurative appendicitis with Blastocystis hominis. Asian Pac J Trop Dis. 2012;2:965-8.

29. Garavelli PL, Seaglione L, Bicocchi R, Libanore M. Pathogenicity of Blastocystis hominis. Infection. 1991;19(3):185.

30. Nassir E, Awad J, Abel AB, Khoury J, Shay M, Lejbkowiez F. Blastocystis hominis as a cause of hypoalbuminemia and anasarca. Eur J Clin Infect Dis. 2004;23(5):399-402.

31. Stensvold CR, Clark CG. Pre-empting Pandora's box: Blastocystis subtypes revisited. Trends Parasitol. 2020;36(3):229-32.

32. Garavelli PL, Libanore M. Blastocystis hominis and blastocystosis (ZierdtGaravelli disease). Ital J Gastroenterol. 1993;25(1):33-6.

33. Davis NA, Islamova Zhl, Giiasov KhZ, Badalova NS, Takhtokhodzhaeva GR, Latipov RR, Osipova SO. Blastocystis hominis and nonpathogenic enteric protozoa in patients with pulmonary tuberculosis and those with HIV infection. Med Parazitol (Mosk). 2010;3:8-11.

34. Zuel-Fakkar NM, Abdel Hameed DM, Hassanin OM. Study of Blastocystis hominis isolates in urticaria: a case-control study. Clin Exp Dermatol. 2011;36(8):908-10.

35. Stensvold CR, Arendrup MC, Jespersgaard C, Mølbak K, Nielsen HV. Detecting Blastocystis using parasitologic and DNA-based methods: a comparative study. Diagn Microbiol Infect Dis. 2007;59(3):303-7.

36. Adıyaman Korkmaz G, Doğruman ALF, Mumcuoğlu İ. Investigation of the presence of Blastocystis spp in stool samples with microscopic, culture and molecular methods. Mikrobiyol Bul. 2015;49(1):85-97.

37. Andersen LO, Vedel Nielsen $\mathrm{H}$, Stensvold CR. Waiting for the human intestinal Eukaryotome. ISME J. 2013;7(7):1253-5.

38. Sharma N, Sharma RK, Tewari S, Chauhan M, Bhatia A. Association of periodontal inflammation, systemic inflammation, and duration of menopausal years in postmenopausal women. Quintessence Int. 2018;49(2):123-31.

39. Zhao H, Chen J, Li X, Sun Q, Qin P, Wang Q. Compositional and functional features of the female premenopausal and postmenopausal gut microbiota. FEBS Lett. 2019;593(18):2655-64.

40. Nourrisson C, Scanzi J, Pereira B, NkoudMongo C, Wawrzyniak I, Cian A, Viscogliosi E, Livrelli V, Delbac F, Dapoigny M, Poirier P. Blastocystis is associated with decrease of fecal microbiota protective bacteria: comparative analysis between patients with irritable bowel syndrome and control subjects. PLOS ONE. 2014:9(11):e111868.

41. Tito RY, Chaffron S, Caenepeel C, Lima-Mendez G, Wang J, Vieira-Silva S, Falony G, Hildebrand F, Darzi Y, Rymenans L, Verspecht C, Bork P, Vermeire S, Joossens M, Raes J. Population-level analysis of Blastocystis subtype prevalence and variation in the human gut microbiota. Gut. 2019;68(7):1180-9.

42. Yason JA, Liang YR, Png CW, Zhang Y, Tan KSW. Interactions between a pathogenic Blastocystis subtype and gut microbiota: in vitro and in vivo studies. Microbiome. 2019;7(1):30.

43. Szkup M, Owczarek AJ, Schneider-Matyka D, Brodowski J, Łój B, Grochans E. Associations between the components of metabolic syndrome and the polymorphisms in the peroxisome proliferator-activated 
receptor gamma (PPAR-y), the fat mass and obesity-associated (FTO), and the melanocortin-4 receptor (MC4R) genes. Aging (Albany NY). 2018;10(1):72-82.

44. Scicluna SM, Tawari B, Clark CG. DNA barcoding of Blastocystis. Protist. 2006;157(1):77-85.

45. Suresh K, Smith H. Comparison of methods for detecting Blastocystis hominis. Eur J Clin Microbiol Infect Dis. 2004;23(2):509-11.

46. González-Moreno O, Domingo L, Teixidor J, Gracenea M. Prevalence and associated factors of intestinal parasitisation: a cross-sectional study among outpatients with gastrointestinal symptoms in Catalonia, Spain. Parasitol Res. 2011;108(1):87-93.

47. El Safadi D, Cian A, Nourrisson C, Pereira B, Morelle C, Bastien P, Bellanger AP, Botterel F, Candolfi E, Desoubeaux G, Lachaud L, Morio F, Pomares C, Rabodonirina M, Wawrzyniak I, Delbac F, Gantois N, Certad $G$, Delhaes $L$, Poirier P, Viscogliosi E. Prevalence, risk factors for infection and subtype distribution of the intestinal parasite Blastocystis sp. from a large-scale multi-center study in France. BMC Infect Dis. 2016;16(1):451.

48. Gągała K, Kołodziejczyk L, Kosik-Bogacka D, Pilecka-Rapacz M. Assessment of the prevalence of intestinal parasite infections among patients at the Laboratory of Department of Biology and Medical Parasitology of the Pomeranian Medical University in Szczecin in the years 1983-2012. Pomeranian J Life Sci. 2020;66(1):5-10.

49. Kaczmarek A, Wesołowska M, Gołąb E, Sałamatin R. Blastocystis spp. infection in young people in Poland. Ann Parasitol. 2019;65:59.

50. Raś-Noryńska M, Białkowska J, Sokół R, Piskorz-Ogórek K. Parasitological stool examination from children without the typical symptoms of parasitic disease. Przegl Epidemiol. 2011;65(4):599-603.

51. Płonka W, Dzbeński TH. The occurrence of intestinal parasites among children attending first classes of the elementary schools in Poland in the school year 1997/1998. Przegl Epidemiol. 1999;53(3-4):331-8.

52. Seyer A, Karasartova D, Ruh E, Güreser AS, Turgal E, Imir T, Taylan-Ozkan A. Epidemiology and prevalence of Blastocystis spp. in North Cyprus. Am JTrop Med Hyg. 2017;96(5):1164-70.

53. Domínguez-Márquez MV, Guna R, Muñoz C, Gómez-Muñoz MT, Borrás R. High prevalence of subtype 4 among isolates of Blastocystis hominis from symptomatic patients of a health district of Valencia (Spain). Parasitol Res. 2008;105(4):949-55.

54. Ramirez JD, Sanchez LV, Bautista DC, Corredor AF, Florez AC, Stensvold CR. Blastocystis subtypes detected in humans and animals from Colombia. Infect Genet Evol. 2014;22:223-8.

55. Stensvold CR, Christiansen DB, Olsen KE, Nielsen HV. Blastocystis sp. subtype 4 is common in Danish Blastocystis-positive patients presenting with acute diarrhea. Am J Trop Med Hyg. 2011;84:883-5.

56. Kaczmarek A, Gołąb E, Żarnowska-Prymek H, Rawska A, Jańczak D, Lewicki A, Wesołowska M, Rożej-Bielicka W, Cielecka D, Sałamatin R. Genetic diversity of Blastocystis hominis sensu lato isolated from humans in Poland. Przegl Epidemiol. 2017;71:539-46.

57. Rudzińska M, Kowalewska B, Wąż P, Sikorska K, Szostakowska B. Blastocystis subtypes isolated from travelers and non-travelers from the north of Poland: a single center study. Infect Genet Evol. 2019;75:103926.

58. Alfellani MA, Stensvold CR, Vidal-Lapiedra A, Onuoha ES, FagbenroBeyioku AF, Clark CG. Variable geographic distribution of Blastocystis subtypes and its potential implications. Acta Trop. 2013;126(1):11-8.

59. Abe N. Molecular and phylogenetic analysis of Blastocystis isolates from various hosts. Vet Parasitol. 2004;120(3):235-42.

60. Meloni D, Sanciu G, Poirier P, El Alaoui H, Chabé M, Delhaes L, Dei-Cas E, Delbac F, Luigi Fiori P, Di Cave D, Viscogliosi E. Molecular subtyping of Blastocystis sp. isolates from symptomatic patients in Italy. Parasitol Res. 2011;109(3):613-61.

61. Yoshikawa H, Wu Z, Pandey K, Pandey BD, Sherchand JB, Yanagi T, Kanbara H. Molecular characterization of Blastocystis isolates from children and rhesus monkeys in Kathmandu, Nepal. Vet Parasitol. 2009;160(3-4):295-300.

62. Rene BA, Stensvold CR, Badsberg JH, Nielsen HV. Subtype analysis of Blastocystis isolates from Blastocystis cyst excreting patients. Am J Trop Med Hyg. 2009;80(4):588-92.

63. Kotłowski A. Blastocystis - an attempt to assess clinical symptoms and the effectiveness of metronidazole treatment in cases of varying degrees of parasitic infection intensity and isolated genotypes of Blastocystis sp. in polish returning from the tropics and not leaving the country. Ann Acad Med Ged. 2012;:XLII.
64. Vogelberg C, Stensvold CR, Monecke S, Ditzen A, Stopsack K, HeinrichGräfe U, Pöhlmann C. Blastocystis sp. subtype 2 detection during recurrence of gastrointestinal and urticarial symptoms. Parasitol Int. 2010;59(3):469-71.

65. Mattiucci S, Crisafi B, Gabrielli S, Paoletti M, Cancrini G. Molecular epidemiology and genetic diversity of Blastocystis infection in humans in Italy. Epidemiol Infect. 2016;144(3):635-46.

66. Stensvold CR, Alfellani MA, Nørskov-Lauritsen S, Prip K, Victory EL, Maddox C, Nielsen HV, Clark CG. Subtype distribution of Blastocystis isolates from synanthropic and zoo animals and identification of a new subtype. Int J Parasitol. 2009;39(4):473-9.

67. Forsell J, Granlund M, Stensvold CR, Clark CG, Evengård B. Subtype analysis of Blastocystis isolates in Swedish patients. Eur J Clin Microbiol Infect Dis. 2012;31(7):1689-96.

68. Santos HL, Sodré C, Demacedo HW. Blastocystis sp. in splenic cysts: causative agent or accidental association? A unique case report. Parasit Vectors. 2014;7:207.

69. Clark CG. Variable geographic distribution of Blastocystis subtypes and its potential implications. Acta Trop. 2013;126(1):11-8.

70. Wang W, Owen H, Traub RJ, Cuttell L, Inpankaew T, Bielefeldt-Ohmann H. Molecular epidemiology of Blastocystis in pigs and their in-contact humans in Southeast Queensland, Australia, and Cambodia. Vet Parasitol. 2014;203(3-4):264-9.

71. Lewicki A, Rozej-Bielicka W, Salamantin R. Blastocystis hominis s. 1. ST6 - parasite of chickens - new zoonotic agent in Poland. Ann Parasitol. 2016;62:203.

72. Ramírez JD, Sánchez LV, Bautista DC, Corredor AF, Flórez AC, Stensvold CR. Blastocystis subtypes detected in humans and animals from Colombia. Infect Genet Evol. 2014;22:223-8.

73. Engsbro AL, Stensvold CR. Blastocystis: to treat or not to treat... but how? Clin Infect Dis. 2012;55(10):1431-2.

74. Sheikh S, Asghari A, Sadraei J, Pirestani M, Zare M. Blastocystis sp. subtype 9: as the first reported subtype in patients with schizophrenia in Iran. SN Compr Clin Med. 2020;2:633-9.

75. Abdulsalam A, Ithoi I, Al-Mekhlafi H, Ahmed A, Surin J, Mak J. Drinking water is a significant predictor of Blastocystis infection among rural Malaysian primary schoolchildren. Parasitology. 2012;139(8):1014-20.

76. Cañete R, Díaz MM, Avalos García R, Laúd Martinez PM, Manuel PF. Intestinal parasites in children from a day care centre in Matanzas City, Cuba. PLoS ONE. 2012;7(12):e51394.

77. Paulos S, Köster PC, Delucio A, Hernández-de-Mingo M, Cardona GA, Fernández-Crespo JC, Stensvold CR, Carmena D. Occurrence and subtype distribution of Blastocystis sp. in humans, dogs and cats sharing household in northern Spain and assessment of zoonotic transmission risk. Zoonoses Public Health. 2018;65(8):993-1002.

78. Zaki M, Zaman V, Sheikh NA. Resistance of Blastocystis hominis cysts to chlorine. J Pak Med Assoc. 1996;46(8):178-9.

79. Rajah-Salim H, Suresh KG, Vellayan S, Mak JW, Khairul AA, Init I, Vennila GD, Saminathan R, Ramakrishnan K. Blastocystis in animal handlers. Parasitol Res. 1999;85(12):1032-3.

80. Abe N, Nagoshi M, Takami K, Sawano Y, Yoshikawa H. A survey of Blastocystis sp. in livestock, pets, and zoo animals in Japan. Vet Parasitol. 2002;106(3):203-12.

81. Chuong LS, Suresh K, Mak JW, Init I, Kathijah O. Prevalence of Blastocystis in animals from domesticated surroundings. Southeast Asian J Trop Med Public Health. 1996;27(4):850-2.

82. Ruaux CG, Stang BV. Prevalence of Blastocystis in shelter-resident and client-owned companion animals in the US Pacific Northwest. PLoS ONE. 2014;9(9):e107496.

83. Belleza ML, Reyes JC, Tongol-Rivera PN, Rivera WL. Subtype analysis of Blastocystis sp. isolates from human and canine hosts in an urban community in the Philippines. Parasitol Int. 2016;65(3):291-4.

84. Duda A, Kosik-Bogacka D, Lanocha-Arendarczyk N, Kołodziejczyk L, Lanocha A. The prevalence of Blastocystis hominis and other protozoan parasites in soldiers returning from peacekeeping missions. Am J Trop Med Hyg. 2015;92(4):805-6.

85. Vanhattem JM, Arcilla MS, Schultsz C, Bootsma MC, Verhaar N, Rebers SP, Goorhuis A, Grobusch MP, Penders J, Dejong MD, Vangool T, Bart A. Carriage of Blastocystis spp. in travellers - a prospective longitudinal study. Travel Med Infect Dis. 2019;27:87-91. 
86. Srichaipon N, Nuchprayoon S, Charuchaibovorn S, Sukkapan P, Sanprasert V. A Simple genotyping method for rapid differentiation of Blastocystis subtypes and subtype distribution of Blastocystis spp. Thailand Pathog. 2019;8(1):38.

87. Hameed DM, Hassanin OM, Zuel-Fakkar NM. Association of Blastocystis hominis genetic subtypes with urticaria. Parasitol Res. 2011;108(3):553-60

88. Yavasoglu I, Kadikoylu G, Uysal H, Ertug S, Bolaman Z. Is Blastocystis hominis a new etiologic factor or a coincidence in iron deficiency anemia? Eur J Haematol. 2008:8(1):47-50.

89. El Deeb H, Khodeer S. Blastocystis spp.: frequency and subtype distribution in iron deficiency anemic versus non-anemic subjects from Egypt. J Parasitol. 2013;99(4):599-602.

90. El Deeb HK, Salah-Eldin H, Khodeer S. Blastocystis hominis as a contributing risk factor for development of iron deficiency anemia in pregnant women. Parasitol Res. 2012;110(6):2167-74.

91. Rostami Nejad M, Nazemalhosseini Mojarad E, Dabiri H, Nochi Z, Pourhoseingholi MA, Sahebekhtiari N, Habibi M, Zali MR. A case-contro study of Blastocystis hominis among Iranian population. East Afr Public Health. 2010;7(1):101-4.

92. Cekin AH, Cekin Y, Adakan Y, Tasdemir E, Koclar FG, Yolcular BO. Blastocystosis in patients with gastrointestinal symptoms: a case-control study. BMC Gastroenterol. 2012;12:122

93. Diaz E, Mondragon J, Ramirez E, Bernal R. Epidemiology and control of intestinal parasites with nitazoxanide in children in Mexico. Am J Trop Med Hyg. 2003;68(4):384-5.

94. Laodim P, Intapan PM, Sawanyawisuth K, Prasongdee TK, Laummaunwai $P$, Maleewong W. Hypoalbuminemia as a predictor of diarrhea caused by Blastocystis hominis. Southeast Asian J Trop Med Public Health. 2013:44(3):374-8.

95. Basak S, Rajurkar MN, Mallick SK. Detection of Blastocystis hominis: a controversial human pathogen. Parasitol Res. 2014;113(1):261-5.

96. Kaneda Y, Horiki N, Cheng X, Tachibana H, Tsutsumi Y. Serologic response to Blastocystis hominis infection in asymptomatic individuals. Tokai J Exp Clin Med. 2000;25(2):51-6.

97. Yan Y, Su S, Lai R, Liao H, Ye J, Li X, Luo X, Chen G. Genetic variability of Blastocystis hominis isolates in China. Parasitol Res. 2006;99(5):597-601.
98. El Deeb HK, Khodeer S. Blastocystis spp.: frequency and subtype distribution in iron deficiency anemic versus non-anemic subjects from Egypt. J Parasitol. 2013;99(4):599-602.

99. Cheng H, Guo Y, Shin JW. Hematological effects of Blastocystis hominis infection in male foreign workers in Taiwan. Parasitol Res. 2003;90(1):48-51.

100. Stenzel D, Dunn L, Boreham P. Endocytosis in cultures of Blastocystis hominis. Int J Parasitol. 1989;19(7):787-91.

101. Chen TL, Chan CC, Chen HP, Fung CP, Lin CP, Chan WL, Liu CY. Clinical characteristics and endoscopic findings associated with Blastocystis hominis in healthy adults. Am J Trop Med Hyg. 2003;69(2):213-6.

102. Levy Y, George J, Shoenfeld Y. Severe Blastocystis hominis in an elderly man. J Infect. 1996;33(1):57-9.

103. Moe KT, Singh M, Howe J, Ho LC, Tan SW, Ng GC, Chen XQ, Yap EH. Experimental Blastocystis hominis infection in laboratory mice. Parasitol Res. 1997;83(4):319-25.

104. Wawrzyniak I, Poirier P, Viscogliosi E, Meloni D, Texier C, Delbac F, El Alaoui H. Blastocystis, an unrecognized parasite: an overview of pathogenesis and diagnosis. Ther Adv Infect Dis. 2013;1 (5):167-78.

105. Poirier P, Wawrzyniak I, Albert A, El AH, Delbac F, Livrelli V. Development and evaluation of a real-time PCR assay for detection and quantification of Blastocystis parasites in human stool samples: prospective study of patients with hematological malignancies. J Clin Microbiol. 2011:49(3):975-83.

106. Karasartova D, Gureser AS, Zorlu M, Turegun-Atasoy B, Taylan-Ozkan A Dolapci M. Blastocystosis in post-traumatic splenectomized patients. Parasitol Int. 2016:65:802-5.

107. Rajič B, Arapović J, Raguž K, Bošković M, Babić SM, Maslać S. Eradication of Blastocystis hominis prevents the development of symptomatic Hashimoto's thyroiditis: a case report. J Infect Dev Ctries. 2015;9(7):788-91.

\section{Publisher's Note}

Springer Nature remains neutral with regard to jurisdictional claims in published maps and institutional affiliations.
Ready to submit your research? Choose BMC and benefit from:

- fast, convenient online submission

- thorough peer review by experienced researchers in your field

- rapid publication on acceptance

- support for research data, including large and complex data types

- gold Open Access which fosters wider collaboration and increased citations

- maximum visibility for your research: over $100 \mathrm{M}$ website views per year

At BMC, research is always in progress.

Learn more biomedcentral.com/submissions 